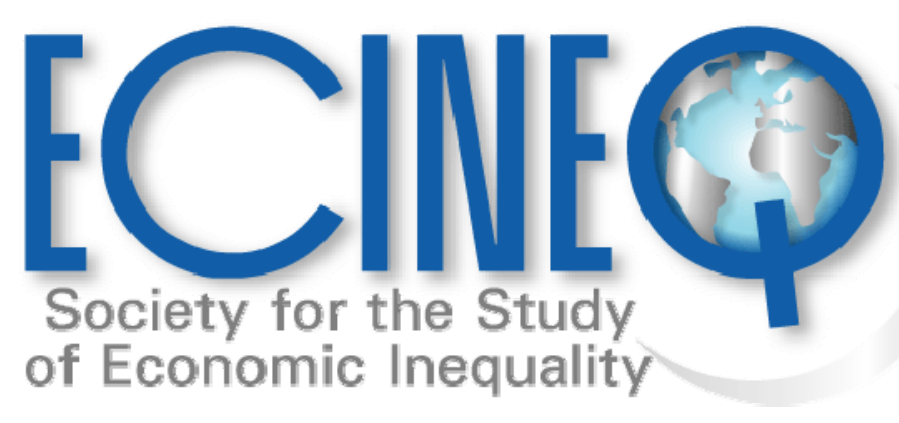

Working Paper Series

The driving force of labor force participation in developed countries

Ivan O. Kitov

Oleg I. Kitov 


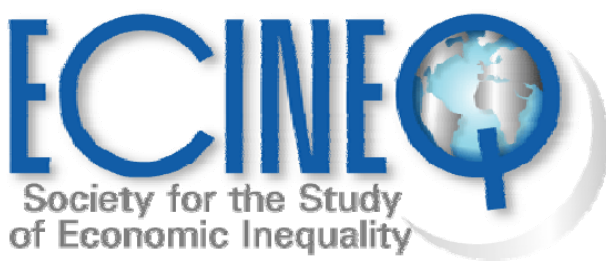

ECINEC 2008-90

June 2008

www.ecineq.org

\title{
The driving force of labor force participation in developed countries
}

\author{
Ivan O. Kitov ${ }^{*}$ \\ Institute for the Geospheres' Dynamics, Russian Academy of Sciences \\ and \\ Oleg I. Kitov \\ $W$ arwick University
}

\begin{abstract}
The evolution of labor force participation rate is modeled using a lagged linear function of real economic growth, as expressed by GDP per capita. For the U.S., our model predicts at a two-year horizon with RMSFE of $0.28 \%$ for the period between 1965 and 2007. Larger part of the deviation between predicted and measured LFP is explained by artificial dislocations in measured time series induced by major revisions to the CPS methodology in 1979 and 1989. Similar models have been developed for Japan, the UK, France, Italy, Canada, and Sweden.
\end{abstract}

JEL Classification: C2, E6, J2

Key words: labor force participation, real GDP per capita, prediction 


\section{Introduction}

The number of people having some paid job or its equivalent and those who are currently unemployed but seek for a job is called the labor force. The ratio of the labor force and overall working age population defines macroeconomic term "participation rate", which provides a measure of labor supply not dependent on population size. Both working age population and labor force participation rate (LFP) vary over time and across countries. Obviously, the level of population of 16 years of age and older is driven by a multitude of factors including social, economic, geographic, and ethnic ones. Conventional economic theories also consider various forces driving the rate of labor force participation (Aaronson et al., 2006; Aaronson, Park, and Sullivan, 2006, 2007; Hausman, 1986; Haveman et al., 1991, Hotchkiss, 2004, 2005; Juhn and Potter, 2006; Murphy and Topel, 1987; Veracierto, 2008; Wachter, 1978; among many others). These theories imply that the evolution and effects of these forces are difficult to forecast (Congressional Budget Office [CBO], 2004). Results of our research support an opposite view and demonstrate that there exists a unique factor completely controlling the evolution of participation rate in developed countries - real economic growth as defined by GDP per capita.

Because of the benefits provided by continuous, extensive, and open statistic information we first analyze and model the rate of labor force participation in the U.S. Figure 1 displays the growth rate of the LFP obtained from its original time series (Bureau of Labor Statistics [BLS], 2008) and a centered five-year moving average, MA(5). The rate rose during the 1960s through 
1980s. Since 2000 it has been decreasing. Previous investigations, Aaronson et al. (2006) and Fullerton (2003) among others, demonstrated that, historically, the change of trend (for example, from the current negative one to a positive one) has not been accurately predicted.

Several models have been developed for the prediction of LFP at various time horizons. Aaronson et al. (2006) proposed a model with cyclical and structural components of the participation rate evolution affected by demographic factors, the business cycle, and other factors. Fallick and Pingle (2007) proposed a model of labor force participation based on cohorts. In their framework, the probability of individual participation declines with age beyond 50. However, Kitov (2005c) showed that there exists an effect of the increasing age of the peak mean income, which counteracts the effect of lowering participation with age. In any case, one can expect significant changes in the LFP due to the ageing of labor supply. Fallick and Pingle also considered the effects of participation trends on the aggregate LFP within all other age groups.

The knowledge of the evolution of labor force participation is crucial for the development of appropriate budgetary, tax, macroeconomic, and financial policy. This is the task for such institutions as the Congressional Budget Office (2004, 2006), the Bureau of Labor Statistic (BLS) (Su, 2007; Toossi, 2005, 2007; Figueroa and Woods, 2007), and the Federal Reserve Banks (FRB San Francisco, 2007; Himmelberg and McConnell, 2005). For example, the CBO (2006)

... developed a microsimulation approach for analyzing Social Security and other longterm policy issues in order to provide the Congress with comprehensive analyses of the budgetary, distributional, and aggregate economic aspects of various policy choices. The microsimulation approach makes it possible to examine how policy affects individuals' benefits under current law and proposed alternatives, including individual accounts.

These models and corresponding LFP projections are characterized by different forecasting accuracy at various time horizons (CBO, 2004). Also, the U.S. Census Bureau (CB) revises the Current Population Survey (CPS) methodology and procedures with possible inconsistencies and incompatibility of data over time (CB, 2002; 2005). In 1979, the Census Bureau applied new population controls obtained in the 1980 census and implemented a new questionnaire. In 1994, the $\mathrm{CB}$ introduced computer-assisted interviewing techniques with new definitions of the labor force concepts (Polivka, 1996; Polivka and Miller, 1998; Polivka and Rothgeb, 1993). The redesigned CPS reports more individuals as being in labor force than did the old survey. This effect is an age-, race-, and gender-dependent, however, and produces artificial steps of different 
height in the time series for various population groups. Such steps result in even higher spikes in the time derivatives of these time series.

Bearing in mind existing economic models for the LFP evolution, numerous factors apparently influencing LFP, and data availability and quality for the U.S. and some other developed countries we have developed a model, which links aggregate LFP to single economic variable - real GDP per capita. This link is fundamental and expresses the inherent trade-off between economic growth and personal income distribution. Our model is quantitatively formulated and tested on the sample of the U.S. and then validated by modeling LFP in other developed countries.

The remainder of the paper is organized as follows. Section 1 presents some working assumptions on quantitative links between labor force participation rate, personal income distribution, the growth rate of real GDP per capita, and the number of 9-year-olds. In Section 2, we test these assumptions and quantitative relationships against actual data and present some predictions of the future evolution of labor force participation rate in the U.S. Section 3 presents results of similar analysis for some other developed counties, which tests and validates the tradeoff between real economic growth and labor force participation rate. Section 4 concludes.

\section{The model}

Our principal assumption consists in the existence of an inherent trade-off between the mechanisms of personal income distribution (PID) and economic growth. In the U.S., personal income distribution has not been changing much since the start of corresponding measurements in 1947 (Kitov, 2007). So, the changes in the rate of economic growth have been accommodated by some changes in relative performance of these mechanisms of income redistribution, not by changes in the distribution itself. Obviously, the rate of participation in labor force, as one of such mechanisms of income redistribution, has been changing over time. Therefore, it is reasonable to start with some features of the PID in the U.S.

The distribution of personal incomes in the U.S. has two branches - quasi-exponential one for incomes from zero to some level, which is called the Pareto threshold. From this threshold, the personal incomes are distributed according to a power law or the Pareto law. Kitov (2005ab) showed that each and every personal income, except the highest $\sim 10 \%$ characterized by the Pareto distribution, grows with an approximately constant annual increment to some critical work experience (Kitov, 2005c). This quasi-constant increment leads to an exponential growth (of average income for given age) with a negative index: $\{1-\exp (-a t)\}$, where $a$ is a small index, $t$ is the working experience. This is a type of satiation process for personal income with age. The process of the average income growth stops when the working experience reaches some critical value, $T_{c r}$. This critical working experience evolves with time as the square root of real GDP per 
capita, as shown by Kitov (2005c). Then, an exponential decay of the average income with work experience is observed. For our purposes, the most important empirical fact is that personal income distribution in the U.S. has been practically not changing, when normalized to contemporary working age population and total personal income (Kitov, 2007). Effectively, fractions of total personal income have been distributed in the same way among the same fractions of the working age population. As a result, the Gini coefficient for the personal incomes reported by the $\mathrm{CB}$ has not been changing over time.

Let's assume that all persons who have a paid job or its equivalent do participate in the production of real GDP. Similarly to the personal income distribution, personal inputs to the real GDP should also be distributed over working population according to some functional dependence on the input. It would be not too inaccurate to assume that these personal inputs to the GDP are exponentially distributed, i.e. the number of people with given input increases exponentially with a decreasing level of the input.

What are qualitative and quantitative effects of real economic growth on LFP considering the fixed (normalized) PID and relevant inputs to the GDP in the U.S.? As shown by Kitov (2006cd), increasing labor supply has no effect on the growth rate of real GDP per capita since the latter depends only on the attained level of real GDP per capita, $G$, and on the changing number of 9-year-olds, $\mathrm{N9}$, according to the following relationship:

$$
d G / G=0.5 d N_{9} / N_{9}+A_{1} / G
$$

or, in the reversed form,

$$
d N_{9} / N_{9}=2\left(d G / G-A_{l} / G\right)
$$

where $A_{l}$ is an empirical constant. The term $A_{l} / G$ can be associated with potential economic growth. In other words, real economic growth in the U.S. would be inversely proportional to the attained level of real GDP per capita if the $N_{9}$ has not been changing. Figure 2 compares the number of 9 -year-olds measured by the Census Bureau and that predicted by $\left(1^{\prime}\right)$, where the estimates of real GDP per capita are borrowed from the Conference Board database (2008). (For the U.S. and other developed countries in this study, GDP per capita in 1990 U.S. dollars is used, i.e. that converted at Geary Khamis PPPs.) Our model explains $80 \%\left(\mathrm{R}^{2}=0.8\right)$ of the variability in real GDP per capita between 1960 and 2006. This is an excellent result considering the accuracy of measurement of both $G$ and $N_{9}$. (Notice that the prediction of real economic growth at a nine-year horizon is natural.)

On the other hand, the growth in real GDP can influence labor force supply through redistribution of personal incomes. Fluctuations in the number of 9-year-olds produce 
fluctuations in real GDP per capita relative to that defined by potential economic growth, $A_{l} / G$, and thus provide variations in personal income relative to some neutral growth rate. The simplest assumption on the redistribution of some excessive (positive) amount of personal income consists in the increase of the fraction of population in labor force. At first glance, more people would be able to obtain paid jobs with extra money in the economy. Surprisingly, this assumption is wrong for the U.S. The intuition behind the mechanism of LFP reaction on the redistribution of the money excess is opposite - less people are forced to seek income through paid job because of other channels (not included in the CPS questionnaire) of personal income redistribution. A smaller part of the working age population receives more income and somehow transfers it to the fraction of the populations not in labor force to recover original PID. When the growth rate of real GDP per capita is below its potential the total personal income grows at a rate below the neutral one and the lack of personal income earned by given labor force has to be compensated by an increase in the LFP. Figure 2 demonstrates that the $N_{9}$ was on a downward trend in the late 1960s and the1970s. Hence, these years are characterized by the growth rate of real GDP per capita below its potential and, thus, by an increasing labor force participation. On the contrary, the years after 1983 have to demonstrate a decreasing rate of the growth in the labor force participation. All these effects can be observed in Figure 1.

The influence of the growth in real GDP on the LFP has to be complicated by the presence of the exponential distribution of personal inputs to real GDP - the number of people with given income roll-off exponentially as a function of income. If the effect of real growth is based on the excess of the total personal income above its potential level, then higher levels of the LFP are more sensitive to real growth. Really, more people can be included in or excluded from the redistribution because of their smaller personal incomes for paid jobs, which are replaced by some other (not measured) mechanisms of personal income earning. It is reasonable to assume that the sensitivity of the LFP to the difference between actual and potential growth rates, $g(t)=d G / G-A_{l} / G$, increases exponentially with increasing LFP. Also, there might be a time delay between action and reaction and the LFP may lag behind the $g(t)$. Now we are ready for a quantitative analysis with a tentative relationship:

$$
\begin{gathered}
\left\{B_{1} d L F P(t) / L F P(t)+C_{1}\right\} \exp \left\{\alpha_{1}\left[L F P(t)-L F P\left(t_{0}\right)\right] / L F P\left(t_{0}\right)=\right. \\
\left.=\int\{d G(t-T)) / G(t-T)-A_{1} / G(t-T)\right\} d t
\end{gathered}
$$

where $B_{1}$ and $C_{1}$ are empirical (country-specific) calibration constants, $\alpha_{1}$ is empirical (also country-specific) exponent, $t_{0}$ is the start year of modeling, $T$ is the time lag, and $d t=t_{2}-t_{1}, t_{1}$ and $t_{2}$ are the start and the end time of the time period for the integration of the $g(t)$ (one year in our 
model). The exponential term defines the change in the sensitivity due to deviation of the LFP from its initial value $\operatorname{LFP}\left(t_{0}\right)$. Effectively, the $L F P(t)$ is a nonlinear function of real economic growth and the trajectory of the $g(t)$ in the past does matter for the attained level of labor force participation.

A simple transformation of (2) using (1) provides another useful form of relationship (2), which relies on the $N_{9}(t)$ instead of the integral of the $g(t)$ :

$$
\left\{B_{2} d L F P(t) / L F P(t)+C_{2}\right\} \exp \left\{\alpha_{2}\left[L F P(t)-L F P\left(t_{0}\right)\right] / L F P\left(t_{0}\right)\right\}=N_{9}(t-T)
$$

where $B_{2}$ and $C_{2}$ are empirical constant different from $B_{1}, C_{1}$, and $\alpha_{2}=\alpha_{1}$.

Historically, we first tried to model $d L F P / L F P$ as a nonlinear function of $G$ and tested a simple relationship similar to (1):

$$
d L F P(t) / L F P(t)=D_{1}\left[d G(t-T) / G(t-T)-A_{2} / G(t-T)\right]+D_{2}
$$

where $D_{1}$ and $D_{2}$ are empirical (country specific) constants, and $A_{2}$ is also an empirical constant, which is different from $A_{l}$ in (1). This model served as a workhorse for those countries, which do not provide accurate estimates of the specific age population. Relationship (4) mimics the nonlinear relationship reciprocal to (2). According to (2) one can rewrite (4) in the following (discrete) form:

$$
\begin{gathered}
N\left(t_{2}\right)=N\left(t_{1}\right)\left\{2\left[d G\left(t_{2}-T\right) / G\left(t_{2}-T\right)-A_{2} / G\left(t_{2}-T\right)\right]+1\right\} \\
d L F P\left(t_{2}\right) / L F P\left(t_{2}\right)=N\left(t_{2}-T\right) / B+C
\end{gathered}
$$

where $N(t)$ is the (formally defined) specific age population, as obtained using $A_{2}$ instead of $A_{1}, B$ and $C$ are empirical constants. Relationship (5) defines the evolution of some specific age population, which is different from actual one. The discrete form is useful for calculations. The difference between (3) and (6) consists in the absence of nonlinear terms in (6). It is worth noting that relationships (4) through (6) represent a formal model and do not pretend to fully substitute the meaning of the specific age population, labor force, and real economic growth implied in (2) and (3).

\section{Modeling the evolution of labor force participation in the U.S.}


As in any empirical analysis, we first discuss availability and quality of relevant data. We use the original source reporting the estimates of labor force participation rate in the U.S. - the BLS (2008). As clear from Figure 1, the original growth rate is characterized by a high volatility induced by relatively low accuracy of corresponding measurements. Therefore, we use MA(5) in our comparisons of observed and predicted time series. One also has to bear in mind that the difference between the LFP measured according to the Census Bureau's definition and some true LFP, which represents the variable for a valid quantitative analysis. Due to numerous revisions to the CB's definition over time this difference is also time dependent and introduces significant noise in the analysis.

Estimates of real GDP per capita can be obtained from many sources. We have chosen the Conference Board database (2008) because it provides PPP estimates for other developed countries what might bring some consistency in the overall cross country comparison. Direct statistical assessment of the uncertainty in the growth rate of the overall real GDP estimates is not available (Fixler and Grimm, 2005), but numerous revisions to corresponding annual estimates indicate that one percentage point is a reasonable value for the uncertainty. Considering about the same uncertainty in the estimates of working age population (CBO, 2004) one can conclude that the accuracy of the estimates of the growth arte of real GDP per capita is not better than 1 percentage point as well. Hence, relative differences of 1 to 2 percentage points between measured and predicted values in this study are inside the uncertainty of original estimates and do not need any additional explanation. The above mentioned revisions to population related variables introduce extra uncertainty, however.

Relationship (3) is the start point of our modeling. Visual fit between predicted and measured $d L F P / L F P$ has been sought. Figure 3 presents results of the $N_{9}(t)$ prediction, which can be replaced with $G$ by (2), using the original LFP time series from the BLS. Corresponding constants are as follows: $t_{0}=1963 ; T=2$ years, $\alpha_{2}=-1.85, B_{2}=-1.5 \mathrm{E}+8, C_{2}=4.94 \mathrm{E}+6$. The predicted time series leads the observed one by two years, i.e. an accurate forecast at a two-year horizon is a natural feature of the model. Coefficient $B_{2}$ is negative what results in a declining rate of the LFP growth during the years of real growth above the potential one, for example, between 1983 and 2000. Exponential term in (3) provides a factor of 0.77 in 2000 (the largest LFP of 67.1\%) relative to 1963 , when the LFP was only $58.7 \%$. This means that $1 \%$ change in $N 9$ at the LFP level of $67.1 \%$ produces a larger change in the $d L F P / L F P$ by factor of $1 / 0.77=1.3$ than $1 \%$ change at the level of $58.7 \%$. Effectively, the sensitivity of the LFP to the N9 is 1.3 times larger. Also displayed is the case without exponential weighting, $\alpha_{2}=0$. This case demonstrates that the specific age population $\left(N_{9}\right)$ is overestimated by the model. 
Considering the uncertainty in the underlying time series $-N_{9}$ and $L F P$, the observed and predicted time series are in a good overall agreement: timing of main turns in both series is excellent and amplitudes of the largest changes are also practically coincide. The measured number of 9-year-olds is characterized by a high uncertainty related to two sources methodology and procedures of measurements in decennial censuses and interpolation of the census estimated between the years of censuses using birth-death-immigration components of the population projection. West and Robinson (1999) estimated the uncertainty in the number of 9year-olds for the 1990 census between $3 \%$ and 5\% in the age group between 5 and 9 years. Especially high revisions to the population estimates are made near census years - as seen from Figure 3. The largest deviations between the predicted and observed population are around the censuses.

So, Figures 2 and 3 demonstrate that real economic growth (or $N_{9}$, which is an equivalent to $G$ ) may explain the evolution of labor force participation rate in the U.S. after 1963. There is another way to invert equations (2) and (3), as represented by relationships (5) and (6). These relationships allow expressing $L F P$ as a nonlinear function of $G$ what facilitates the prediction of labor supply. At the same time, relationships (5) and (6) are just a useful approximation in the case when necessary population estimates are absent or poor. Figure 4 depicts the observed and predicted relative change rate of the LFP. The latter is obtained from (5) and (6) with the following constants and coefficients: $N(1959)=4.5 \mathrm{E}+6, A_{2}=\$ 350, B=-1.23 \mathrm{E}+8, C=0.04225$. Notice that coefficient $A_{2}$ is smaller than $A_{1}=\$ 398$ in (1). Due to high volatility of the original $d L F P / L F P$ time series we compare the predicted time series to MA(5) of the observed series corresponding linear regression is shown in the lower panel of Figure 4. The goodness-of-fit is high: $\mathrm{R}^{2}=0.73$. More important is that timing of main turns in the observed time series is well predicted at a two-year horizon - the predicted series is still two years ahead of the observed one: $T=2$ years. Figure 5 displays the evolution of the $g(t)$ and its cumulative value. Since $A_{2}<A_{l}$, the cumulative value of $g(t)$ has a strong positive trend after 1983. Reciprocally, the $d L F P / L F P$ is characterized by a negative trend.

Having the prediction of the $d L F P / L F P$ from the $G$, one can predict the $L F P$ itself. Figure 6 compares the original labor force participation rate and that obtained from the predicted time series presented in Figure 4. Both curves are synchronized due to a two-year back-shift of the predicted curve. There are three major deviations between the curves - all are associated with large revisions to the original LFP. The root-mean-square forecasting error (RMSFE) of the LFP at a two year horizon for the period between 1968 and 2006 is $0.28 \%$. This accuracy is slightly larger than that inherent to the original time series (from $0.1 \%$ to $0.2 \%$ ) and, noticeably, obtained 
using raw data. The elimination of the most obvious (artificial) deviations induced by the revisions to the CPS results in RMSFE $=0.2 \%$.

Relationship (1) provides a unique opportunity to foresee the evolution of the LFP 11 years ahead. Really, the number of 9-year-olds can be predicted from the younger birth cohorts and additional two years are given by the lag of the LFP behind real economic growth. Figure 7 shows qualitatively what will be the direction of the LFP evolution. It displays the projections of $N_{9}$ and $d N_{9} / N_{9}$ using 6- and 1-year-olds, as available by the end of 2007 . The years 2007 through 2010 are the turning ones for real economic growth - the negative trend observed between 2000 and 2009 should be switched to a positive one. But even poor years for the U.S. economy between 2001 and 2010 are characterized by a negative trend in the $d L F P / L F P$, as Figure 4 demonstrates. This effect is related to the difference between $A_{1}$ and $A_{2}\left(A_{1}>A_{2}\right)$ - even real economic growth at a rate slightly below its potential value $A_{1} / G$ is still above the $A_{2} / G$, which is the watershed for the growth rate of the LFP. Really nasty years, i.e. those with very low or even negative $d G / G$, are necessary to change the negative $(d L F P / L F P)$ trend to a positive one.

The acceleration of real economic growth, which will be observed after 2010, will also bring additional acceleration to the process of the declining labor force participation rate, as Figure 8 demonstrates. The effect of the declining LFP will be mapped into a slowdown in the growth in labor force itself. As a consequence, inflation will drop close or below zero (Kitov, 2006ef; Kitov, Kitov, Dolinskaya, 2007a). All in all, the Golden Era will come back - real economic growth above its potential, low inflation, and low participation rate - the middle class has enough money to run families. What could be better?

\section{Modeling the evolution of LFP in developed countries}

There are two general methods to validate empirical relationships - to extend data set for one system or to describe with the same model the evolution of similar systems over the same time interval. In Section 2, we demonstrated the accuracy of our empirical model linking LFP and real economic growth in the U.S. for the period between 1963 and 2006. In this Section, we extend our approach and model LFP to some other developed countries. One can consider this study as a validation of the model for the U.S. Therefore, we just present quantitative results not discussing them in details.

We begin with the closest neighbor of the U.S. - Canada. The upper panel in Figure 9 depicts the observed and predicted rate of LFP change. The predicted time series is obtained using the following coefficients in (5) and (6): $N(1959)=270000, A_{2}=\$ 342, B=4.0 \mathrm{E}+6, C=-$ 0.0607. We did not use linear regression to obtain these coefficients. In order to obtain the best fit, only visual similarity between cumulative values was sought. In many aspects, the approach 
based on cumulative representation provides a useful constraint on the coefficients in relationships (5) and (6) due to high sensitivity of cumulative values to small disturbances and deviations (Kitov, Kitov, Dolinskaya, 2007ab). This constraint is similar to mass and energy conservation law in physics. Regression usually underestimates coefficients in linear relationships. The lower panel in Figure 9 presents the measured LFP and that obtained from the predicted $d L F P / L F P$ in the upper panel. One can observe an excellent agreement in timing and amplitudes of the changes in both LFPs - mainly these curves coincide. This agreement supports our assumption that real economic growth completely defines the evolution of LFP in developed countries. The difference between the cumulative curves is likely defined by measurement noise. Therefore, no other factors are needed for the description of the observed LFP.

Canada provides one of the best examples of successful modeling for the entire period between 1960 and 2006 and s also characterized by a wide $d L F P / L F P$ dynamic range: from $1.0 \mathrm{E}-2\left[\mathrm{y}^{-1}\right]$ to $+2.0 \mathrm{E}-2\left[\mathrm{y}^{-1}\right]$, with the LFP changing from $55.9 \%$ in 1963 to $67.4 \%$ in 2006 . Dynamic range is a crucial characteristic for any empirical study because it defines resolution. The wider is the dynamic range the higher is the resolution, for the same signal to noise ratio. The noise is defined by the uncertainty in corresponding measurements. As mentioned above, cumulative (or integral) values significantly improve the resolution due to larger incoming signals.

The modeling of the evolution of labor force participation in Italy has also been successful. The upper panel in Figure 10 displays the measured and predicted $d L F P / L F P$. The later is obtained using the following coefficients: $N(1959)=570000, A_{2}=\$ 270 ; B=1.3 \mathrm{E}+7, C=-$ $0.0667, T=0$. (Notice a relatively low value of $A_{2}$.) Linear regression of the time series in the upper panel (between 1963 and 2006) is characterized by $\mathrm{R}^{2}=0.71$.

The lower panel in Figure 10 shows that the dynamic range of LFP for Italy is also wide from $56.1 \%$ in 1960 to $47.2 \%$ in 1984 . The predicted cumulative curve is very close to the measured one over the entire period between 1960 and 2006. This is a clear indication that real economic growth completely defines the evolution of labor force participation in Italy. Small deviations are potentially induced by measurement noise and revisions to labor force definitions.

France is an opposite example of a country with a narrow range of LFP change and, correspondingly, low growth rate, $d L F P / L F P$. The upper panel in Figure 11 indicates that absolute value of the change rate is generally below 0.003 [y $^{-1}$ ] between 1963 and 2000. The LFP, as the lower panel in Figure 11 shows, dropped quickly between 1960 and 1963 - from $59.5 \%$ to $57 \%$. This period is described relatively well with our model. The period between 1997 and 2005, is characterized by an increase in the LFP from $55.6 \%$ to $57 \%$. We failed to simulate this period with our model, but the deviation between the observed and predicted rates are 
relatively small: $\sim 0.005\left[\mathrm{y}^{-1}\right]$. The cumulative curve related to the predicted $d L F P / L F P$ also deviates from the observed LFP. Due to the narrow dynamic range, it is difficult to associate this deviation with one principal source. This deviation does not deny the model, however.

Japan and the UK, presented in Figure 12 and 13, respectively, are very similar in an accurate prediction of $d L F P / L F P$ from both $G$ and the specific age population: 18 years of age for Japan and 9-years of age for the UK (Kitov, 2006bd). Coefficients for corresponding models are given in figure captions. These accurate predictions, however, span a narrower period after 1970. The predicted curves describe amplitudes and timing of major turns in the observed curves. This is a principal feature because conventional LFP models are based on the extrapolation of existing (mainly linear) trends and do not foresee any turns. Our model allows prediction of the LFP evolution in Japan at 18-year horizon! The discrepancy before 1970 are not well explained and might be linked to revisions to labor force and real economic growth definitions, and measurement errors.

Labor force participation in Sweden has been also well described after 1975, as Figure 14 shows. It is similar to Japan and the UK but there are no independent estimates provided by specific age population. The dynamic range of the $d L F P / L F P$ changes is also not specifically

wide - from $-0.008\left[\mathrm{y}^{-1}\right]$ to $+0.002\left[\mathrm{y}^{-1}\right]$. Cumulative curves are very close in the lower panel of Figure 14.

Six countries were analyzed and all demonstrated results positive for the validation of our model with real economic growth driving labor force participation. Apparently, more investigations are necessary including revisions to data compatibility and quality. A straightforward extension would be the inclusion of other developed countries. There is also a mystery associated with the fact that the effect of real growth on LFP in all studied countries is opposite to that in the U.S., where coefficient $B$ is negative.

\section{Conclusion}

There exist a trade-off between real economic growth and the evolution of labor force in developed countries. Moreover, the results obtained in this study for the period between 1960 and 2007 quantitatively support the assumption that real GDP per capita is likely to completely define LFP.

One fundamental difference between the U.S. and other countries consists in the opposite signs of coefficient $B$ : negative for the U.S. and positive for all other studied countries. Effectively, the U.S. is the only country where an elevated real economic growth results in decreasing labor force participation. Such a striking contrast in labor force behavior needs a special analysis. 
The evolution of the aggregate LFP puts a strong constrain on the evolution in various agegender-race groups. It is likely that the mechanism of the influence of real economic growth on LFP in these groups is essentially the same. Therefore, the poorest (in average) age groups with the lowermost LFP are less sensitive to real economic growth - youngest and eldest people are among them.

In any case, the obtained empirical relationships are useful in predictions of LFP in developed countries. The prediction of a drop in the LFP in the U.S. in 2010 can significantly contribute to the model validation. 


\section{References}

Aaronson, S., Fallick, B., Figura, A., Pingle, J.,Wascher, W., (2006). The Recent Decline in the Labor Force Participation Rate and Its Implications for Potential Labor Supply, Brookings Papers on Economic Activity, Economic Studies Program, The Brookings Institution, vol. 37(2006-1), pp. 69-154.

Aaronson, D., Park, K.-H., Sullivan, D., (2006). The Decline in Teen Labor Force Participation. Economic Perspectives, Federal Reserve Bank of Chicago, 30(1), pp. 2-18.

Aaronson, D., Park, K.-H., Sullivan, D., (2007). Explaining the decline in teen labor force participation, Chicago Fed Letter, No. 234.

Bureau of Labor Statistics, (2008). Employment and Unemployment. Table - Labor Force Statistics from the Current Population Survey, retrieved from http://www.bls.gov/cps/cpsatabs.htm, March 30, 2008.

Census Bureau, (2008). Population estimates, retrieved from http://www.census.gov/ popest/estimates.php, March 30, 2008.

Conference Board, (2008). Total Economy Database, retrieved from http://www. conference-board.org/economics/database.cfm, March 30, 2008.

Congressional Budget Office, (2004). Projecting Labor Force Participation and Earnings in CBO's Long-Term Microsimulation Model, Background Paper, October.

Congressional Budget Office, (2006). CBO’s Projections of the Labor Force, September.

Fallick, B., Pingle, J., (2007). The Effect of Population Aging on Aggregate Labor Supply in the U.S., Boston FRB, May, http://www.bos.frb.org/labor2007/papers/pingleII.pdf

Figueroa, E., Woods, R., (2007). Industry output and employment projections to 2016, Monthly Labor Review, November, pp. 53-85.

Fixler, D., Grimm, B. (2005). Reliability of the NIPA Estimates of U.S. Economic Activity, BEA, http://www.bea.gov/bea/ARTICLES/2005/02February/0205_NIPAs.pdf

FRB San Francisco, (2007). Labor Force Participation and the Prospects for U.S. Growth, Economic Letter, No. 2007-33, November 2.

Fullerton, H.R., Jr., (2003). Evaluating the BLS labor force projections to 2000, Monthly Labor Review, October, pp. 3-13.

Hausman, J. A., (1986). Taxes and Labor Supply. In Handbook of Public Economics, v. 1, edited by A. Auerbach and M. Feldstein, North-Holland.

Haveman, R., de John, P., Wolfe, B., (1991). Disability Transfers and the Work Decision of Older Men. The Quarterly Journal of Economics, 106(3), pp. 939-49. 
Himmelberg, C., McConnell, M.M. (2005). How Much Labor Market Slack: The Importance of Adjusting for Trend Participation Rates. Unpublished paper. Federal Reserve Bank of New York (January).

Hotchkiss, J.L., (2004). Employment Growth and Labor Force Participation: How Many Jobs Are Enough? Federal Reserve Bank of Atlanta, Working Paper 2004-25, October.

Hotchkiss, J.L., (2005). What's Up with the Decline in Female Labor Force Participation? Federal Reserve Bank of Atlanta, Working Paper 2005-18, August.

Juhn, C., Potter, S., (2006). Changes in Labor Force Participation in the United States, Journal of Economic Perspectives, American Economic Association, vol. 20(3), pages 27-46.

Kitov, I., (2005a). A model for microeconomic and macroeconomic development, Working Papers 05, ECINEQ, Society for the Study of Economic Inequality. http://ideas.repec.org/p/inq/inqwps/ecineq2005-05.html

Kitov, I., (2005b). Evolution of the personal income distribution in the U.S.: High incomes, Working Papers 02, ECINEQ, Society for the Study of Economic Inequality. http://ideas.repec.org/p/inq/inqwps/ecineq2005-02.html

Kitov, I., (2005c). Modelling the average income dependence on work experience in the U.S. from 1967 to 2002, Working Papers 11, ECINEQ, Society for the Study of Economic Inequality. http://ideas.repec.org/p/inq/inqwps/ecineq2005-11.html

Kitov, I., (2006a). Modelling the age-dependent personal income distribution in the U.S., Working Papers 17, ECINEQ, Society for the Study of Economic Inequality. http://ideas.repec.org/p/inq/inqwps/ecineq2006-17.html

Kitov, I., (2006b). The Japanese economy, MPRA Paper 2737, University Library of Munich, Germany. http://ideas.repec.org/p/pra/mprapa/2737.html

Kitov, I., (2006c). Real GDP per capita in developed countries, MPRA Paper 2738, University Library of Munich, Germany. http://ideas.repec.org/p/pra/mprapa/2738.html

Kitov, I., (2006d). GDP growth rate and population, Working Papers 42, ECINEQ, Society for the Study of Economic Inequality. http://ideas.repec.org/p/inq/inqwps/ecineq200642.html

Kitov, I. (2006e). Inflation, unemployment, labor force change in the USA, Working Papers 28, ECINEQ, Society for the Study of Economic Inequality, http://ideas.repec.org/p/inq/inqwps/ecineq2006-28.html

Kitov, I., (2006f). Exact prediction of inflation in the USA, MPRA Paper 2735, University Library of Munich, Germany, http://ideas.repec.org/p/pra/mprapa/2735.html

Kitov, I., (2007). Modeling the evolution of Gini coefficient for personal incomes in the USA between 1947 and 2005, Working Papers 67, ECINEQ, Society for the Study of Economic Inequality, http://ideas.repec.org/p/inq/inqwps/ecineq2007-67.html 
Kitov, I., Kitov, O., Dolinskaya, S., (2007a). Inflation as a function of labor force change rate: cointegration test for the USA, MPRA Paper 2734, University Library of Munich, Germany, http://ideas.repec.org/p/pra/mprapa/2734.html

Kitov, I., Kitov, O., Dolinskaya, S., (2007b). Modelling real GDP per capita in the U.S.: cointegration test, MPRA Paper 2739, University Library of Munich, Germany. http://ideas.repec.org/p/pra/mprapa/2739.html

Murphy, K. M., Topel, R.H., (1987). The Evolution of Unemployment in the United States: 1968-1985. In NBER Macroeconomics Annual 1987. Edited by S. Fischer. The MIT Press.

Polivka, A. E, (1996). Data Watch: The Redesigned Current Population Survey. Journal of Economic Perspectives, 10(3), pp. 169-80.

Polivka, A. E. , Miller, S.M., (1998). The CPS After the Redesign: Refocusing the Economic Lens. In Labor Statistics and Measurement Issues, edited by J. Haltiwanger, M. Manser, and R. Topel. University of Chicago Press.

Polivka, A. E., Rothgreb, J.M., (1993). Overhauling the Current Population Survey: Redesigning the Questionnaire. Monthly Labor Review, 116(September), pp. 10-28.

Su, B., (2007). The U.S. economy to 2016: slower growth as boomers begin to retire, Monthly Labor Review, November, pp. 13-32.

Toossi, M. (2005). Labor Force Projections to 2014: Retiring Boomers. Monthly Labor Review 128(November), pp. 25-44.

Toossi, M., (2007). Labor force projections to 2016: more workers in their golden years, Monthly Labor Review, November, pp. 33-52.

U.S. Census Bureau. (2002). Technical Paper 63RV: Current Population Survey - Design and Methodology, issued March 2002. Retrieved February 26, 2007 from http://www.census.gov/prod/2002pubs/tp63rv.pdf.

U.S. Census Bureau. (2005). Changes in Methodology for the March Current Population Survey, Retrieved February 26, 2007 from http://www.census.gov/hhes/www/income/histinc/hstchg.html.

Veracierto, M., (2008). On the cyclical behavior of employment, unemployment and labor force participation, Federal Reserve Bank of Chicago, February. 545-76.

Wachter, M. L., (1978). Intermediate Swings in Labor Force Participation, BPEA, 2, pp.

West, K.K., Robinson, J. G.,(1999). What Do We Know About the Undercount of Children? US Census Bureau working paper, Issued August 1999. http://www.census.gov/population/www/documentation/twps0039/twps0039.html 
Figures

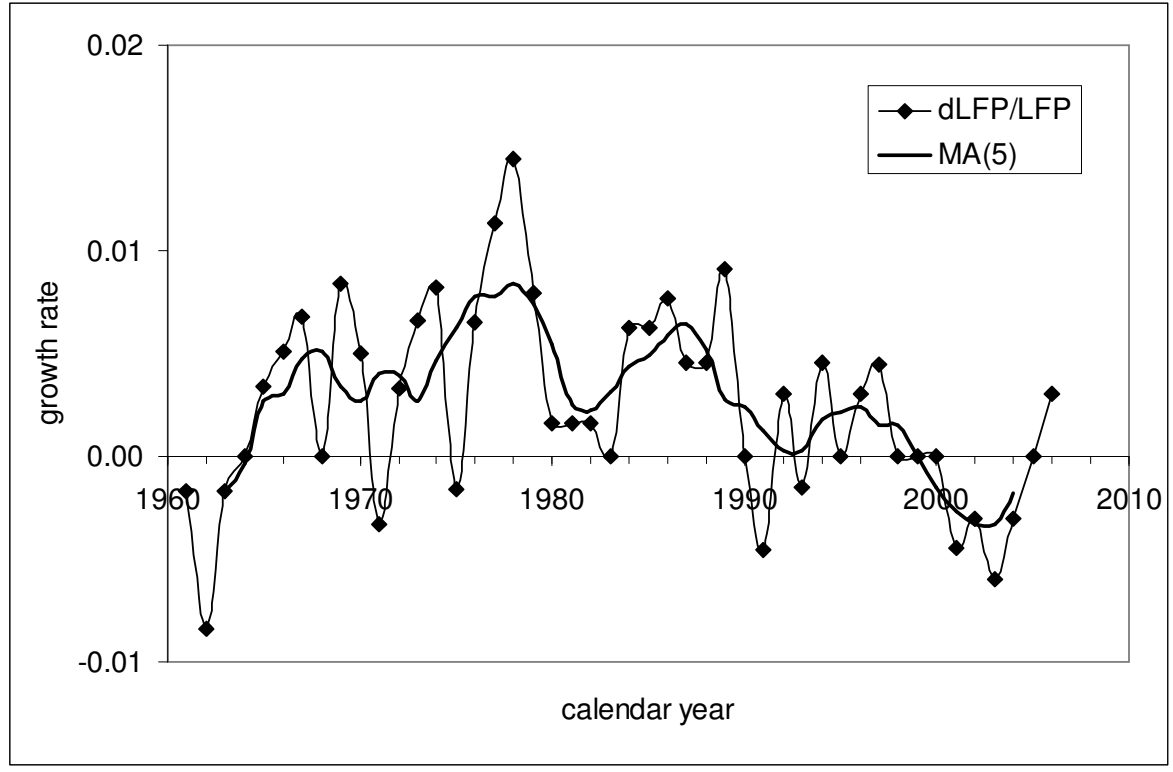

Figure 1. The growth rate of labor force participation (LFP) in the U.S. between 1960 and 2007 as reported by the Bureau of Labor Statistics. The original time series is smoothed by a centered 5-year moving average, MA(5). Notice the increase in the growth rate of the LFP since 2003. 

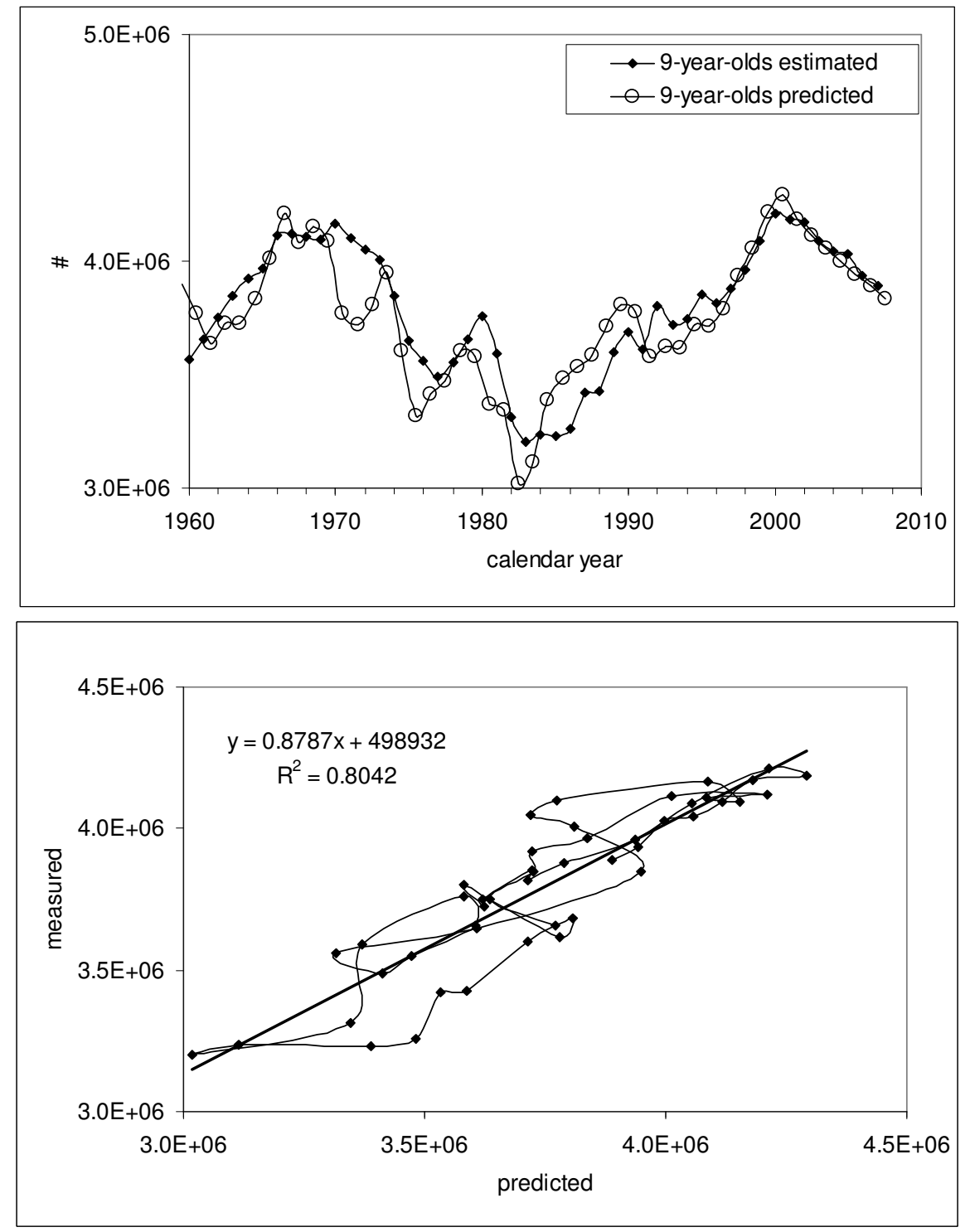

Figure 2. Observed and predicted number of 9-year-olds in the U.S. The predicted number is obtained from the estimates of real GDP per capita according to (1) with $A_{1}=\$ 398$ (1990 U.S. dollars). Notice that this relationship demonstrates a non-linear link between the number of 9year-olds and the growth rate of real GDP per capita. It is presumed in this study that the latter variable is the driving force of the growth in labor force participation rate. Linear regression is also depicted in the lower panel and provides an estimate of the goodness-of-fit: $\mathrm{R}^{2}=0.8$. 


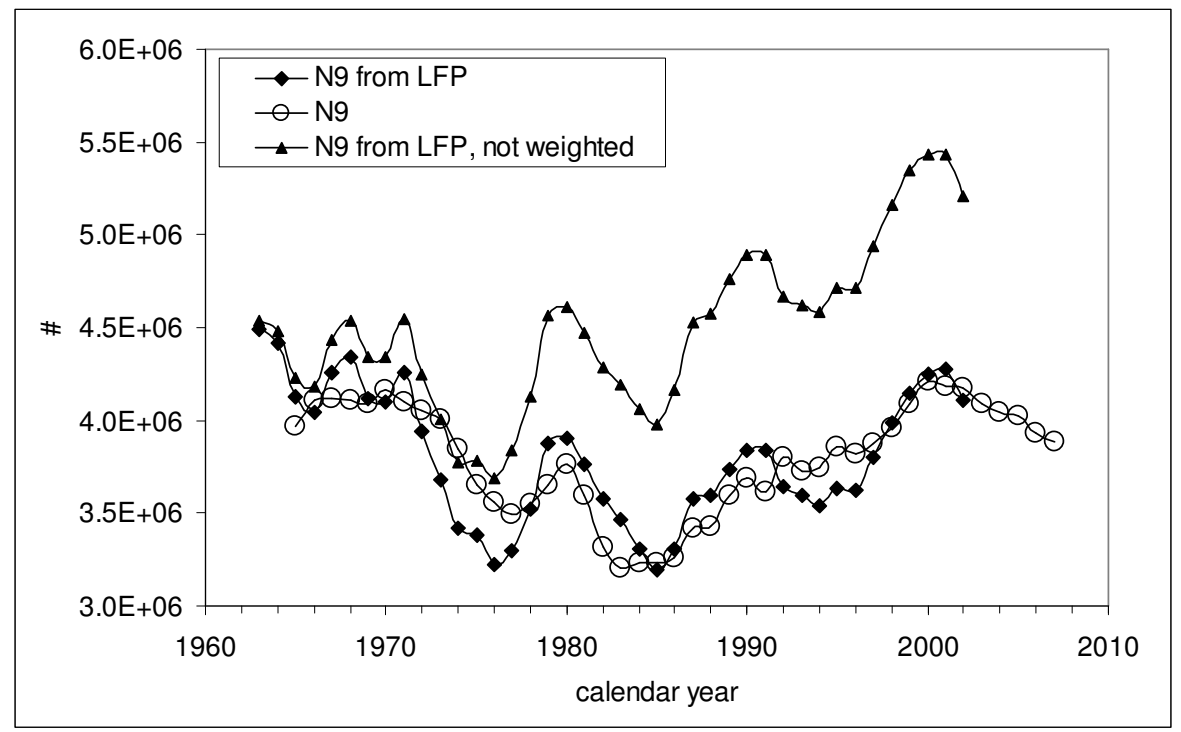

Figure 3. The number of 9-year-olds: the observed one and that obtained from the LFP with and without exponential weighting in (3). Constants $t_{0}=1963 ; B_{2}=-1.5 \mathrm{E}+8, C_{2}=4.94 \mathrm{E}+6, \alpha_{2}=-1.85$. Also shown is the case with $\alpha_{2}=0: N_{9}$ is overestimated. 

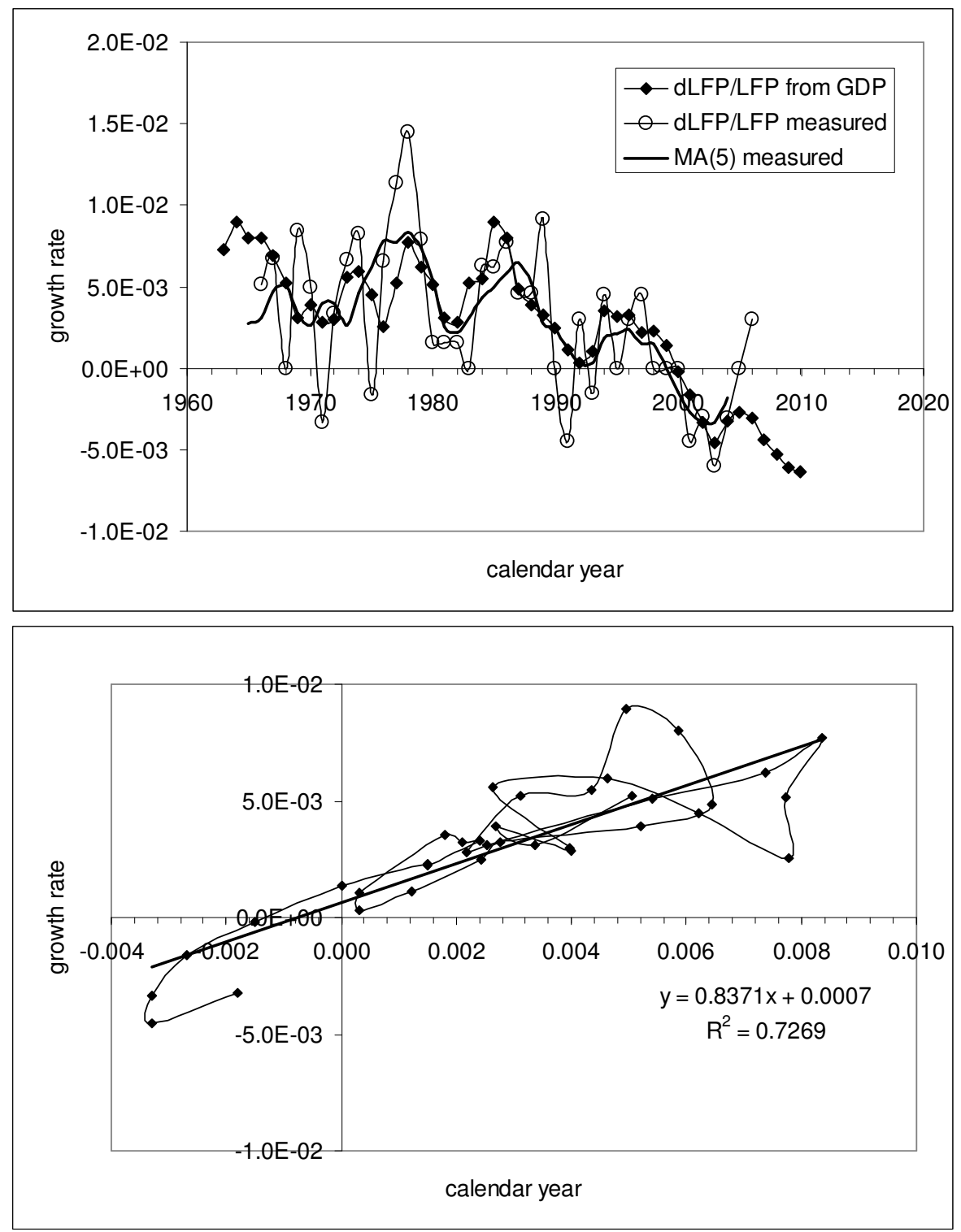

Figure 4. Observed and predicted growth rate of LFP in the U.S. The latter is obtained from real GDP per capita using (5) and (6) with $N(1959)=4.5 \mathrm{E}+6, A_{2}=\$ 350$ (1990-dollars), $B=-1.23 \mathrm{E}+8$, $C=0.04225$.

The lower panel presents a regression of the observed time series on the predicted with $\mathrm{R}^{2}=0.73$. 


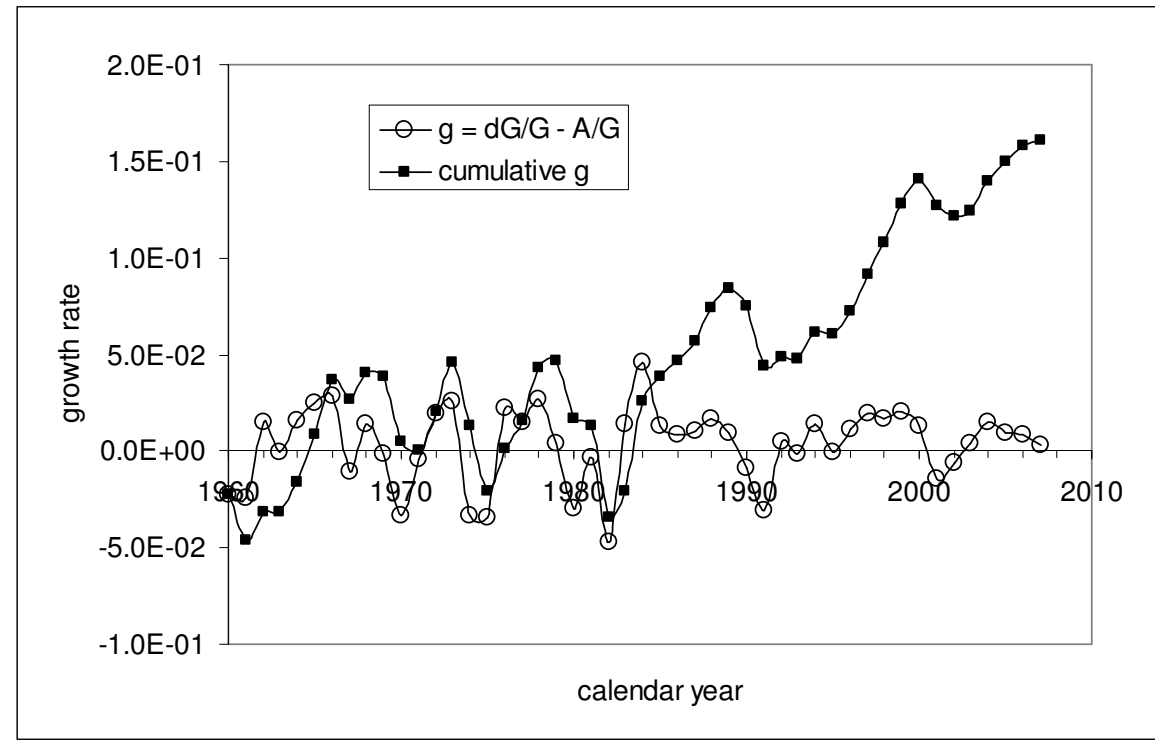

Figure 5. Evolution of the transient part, $g(t)$, of the growth rate of real GDP per capita, $G$ : $g(t)=d G(t) / G(t)-A_{2} / G(t)$, where $A_{2}=\$ 350$ (1990-dollars) is empirical (and country-specific) constant.

Also shown is the cumulative value of the transient part. Notice the growth of the cumulative value since 1983. 


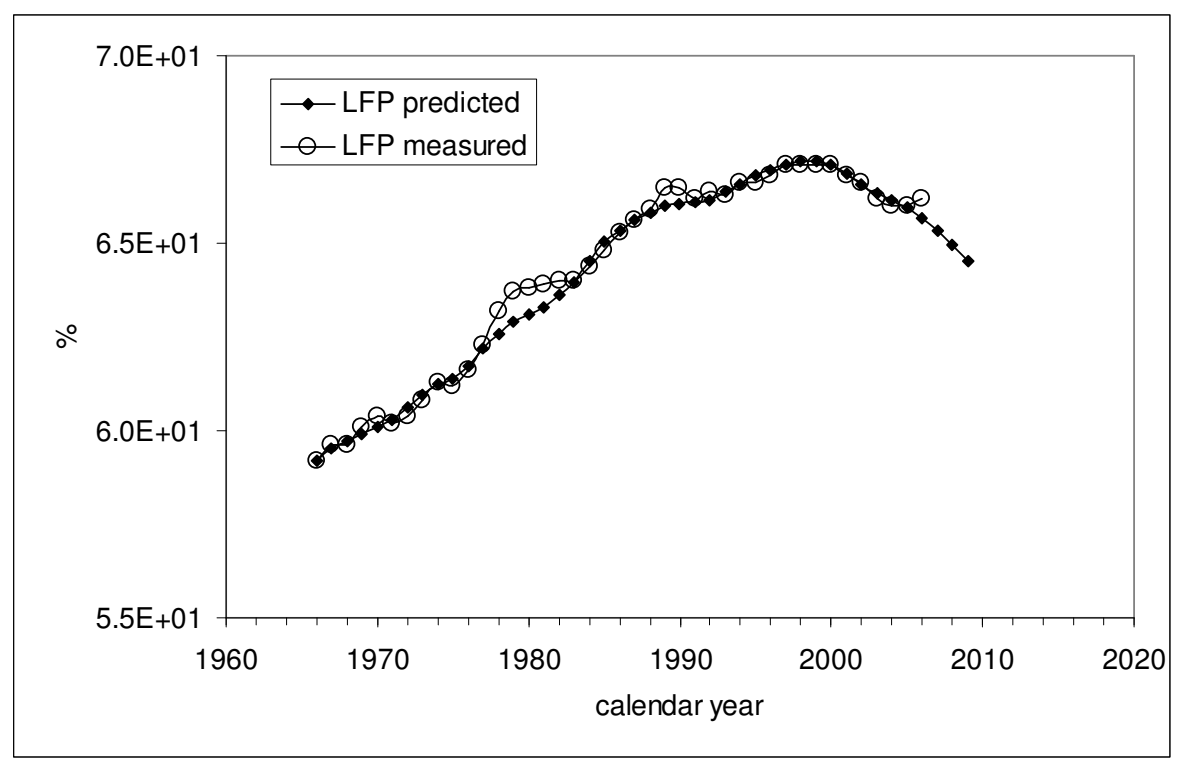

Figure 6. Observed and predicted LFP in the U.S. The latter is obtained from the growth rate time series presented in Figure 5. Notice the largest deviation between the curves is associated with the years of major revisions to the LFP - 1980 and 1990. 
a)

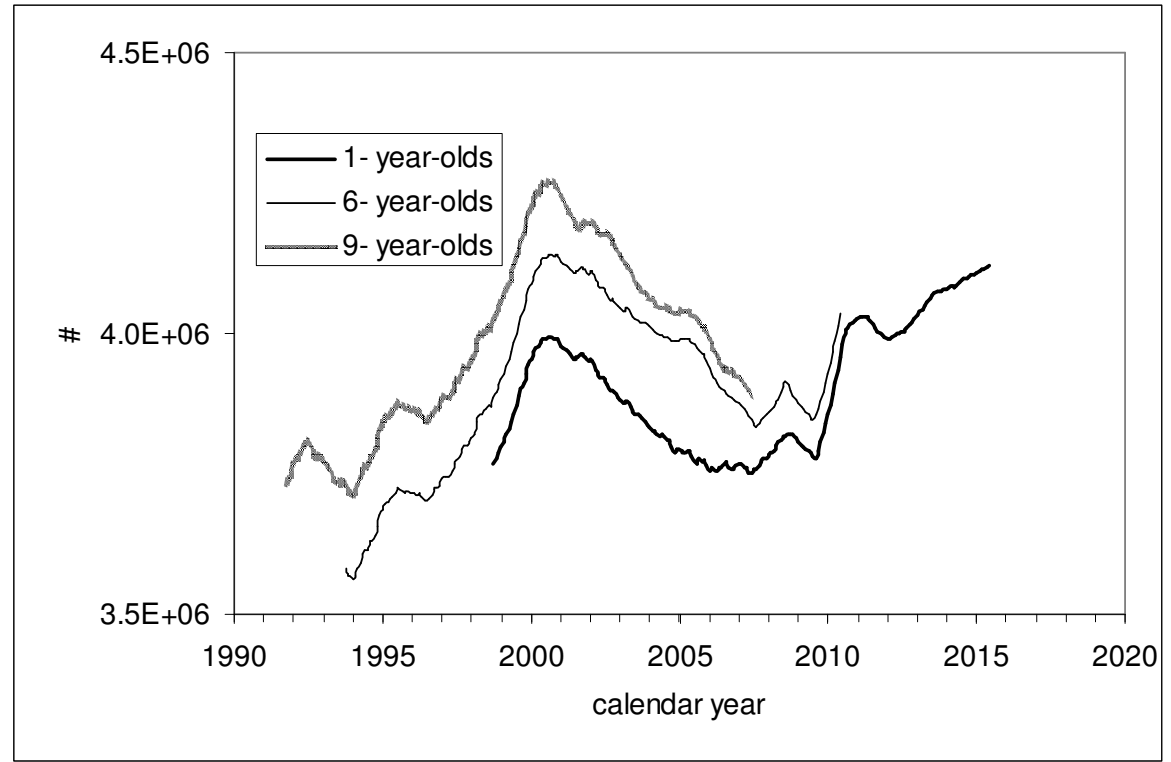

b)

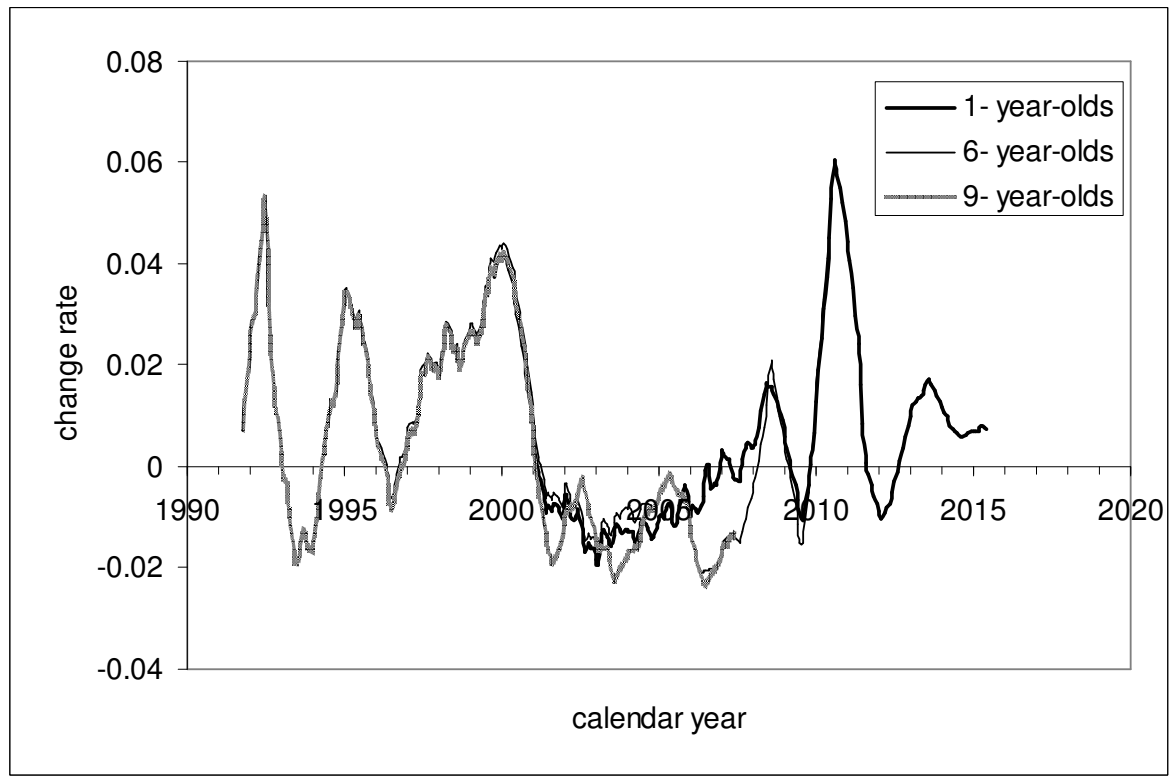

Figure 7. Prediction of the number of 9-year-olds by extrapolation of population estimates for younger ages (1- and 6-year-olds).

a) Total population estimates. The time series for younger cohorts are shifted ahead by 8 and 3 years, respectively.

b) The change rate of the population estimates given in a), which is proportional to the growth rate of real GDP per capita. Notice the difference in the change rate provided by 1-year-olds and 6-year-olds for the period between 2003 and 2010. This discrepancy is related to the agedependent difference in population revisions. 


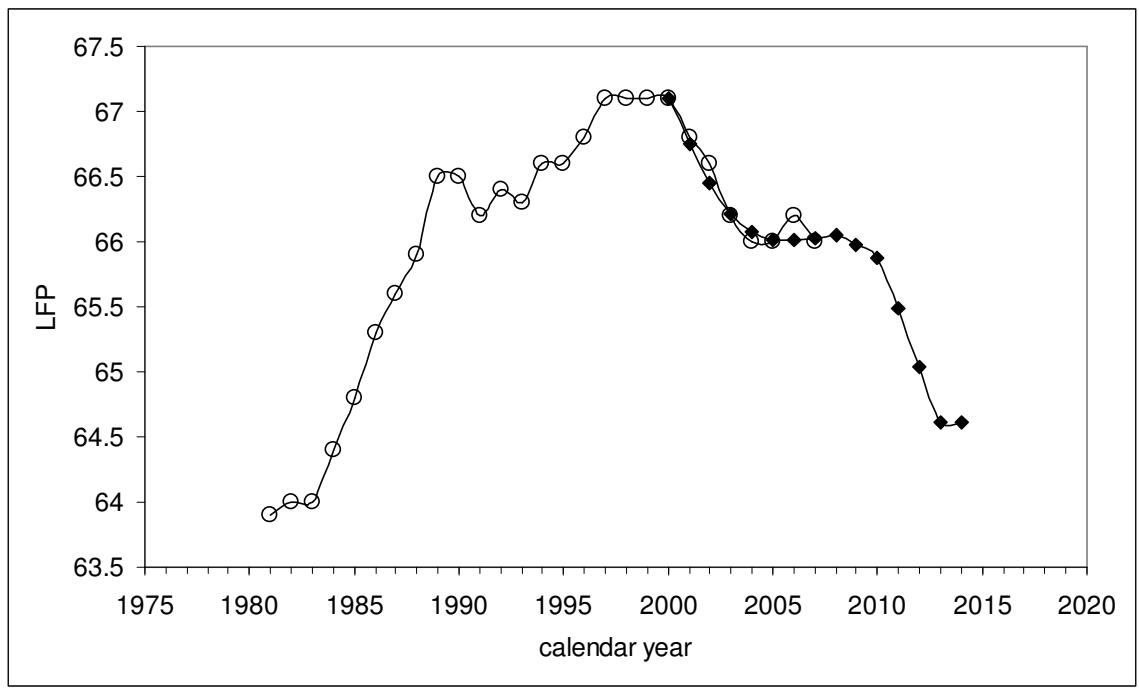

Figure 8. Prediction of the LFP evolution in the USA between 2000 and 2014 from the number of 3-year-olds. Flat segment between 2004 and 2009 will end up in a rapid drop by $1.3 \%$ after 2010. This is the effect of an elevated (above potential) real economic growth. 

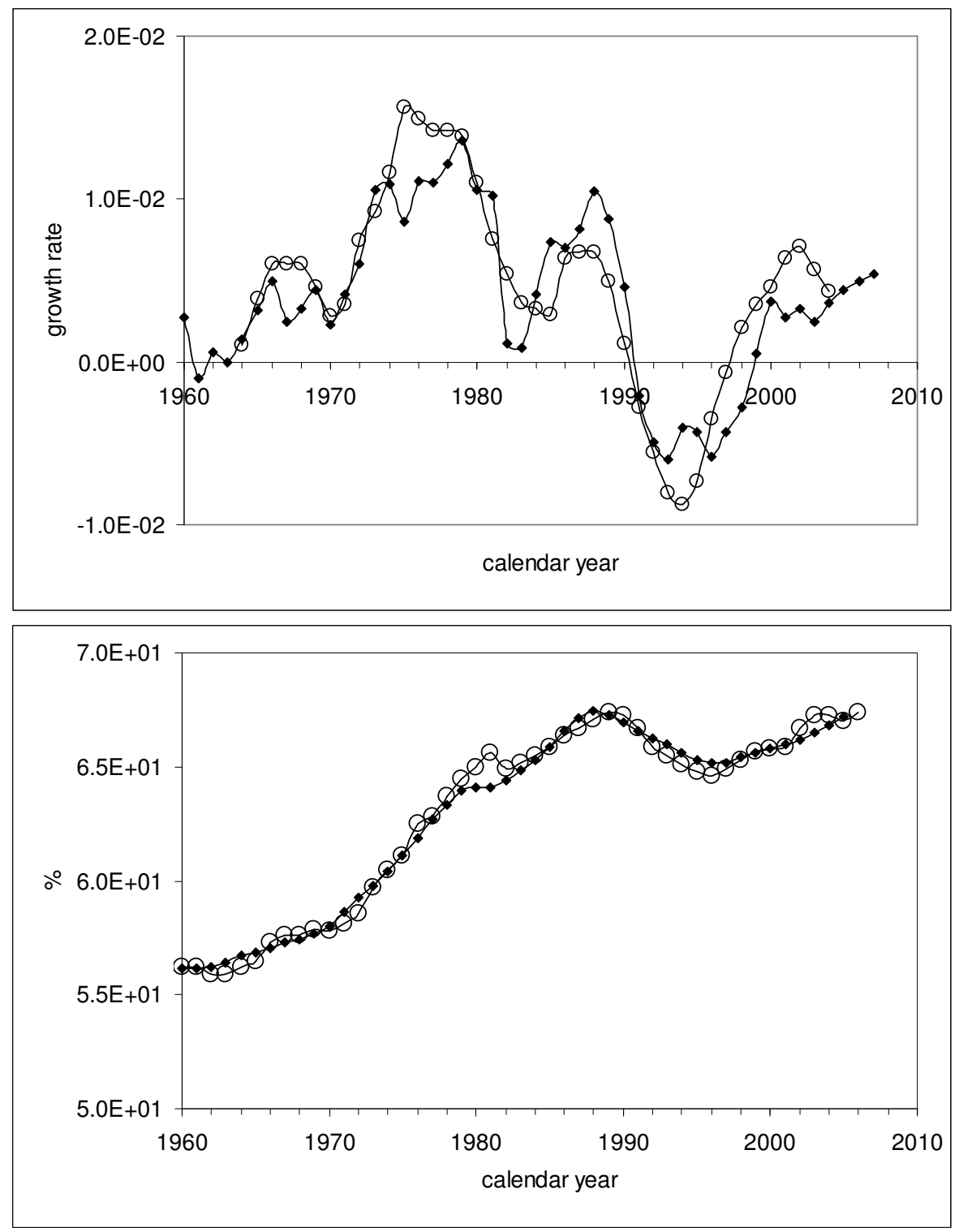

Figure 9. Upper panel: observed $[\mathrm{MA}(5)]$ and predicted growth rate of LFP in Canada: $N(1959)=270000, A_{2}=\$ 342$ (1990 U.S. dollars), $B=4.0 \mathrm{E}+6, C=-0.0607, T=0$ years. For the period between 1963 and 2006, a linear regression gives the goodness-of-fit, $R^{2}=0.78$.

The lower panel depicts the observed and predicted LFP. 

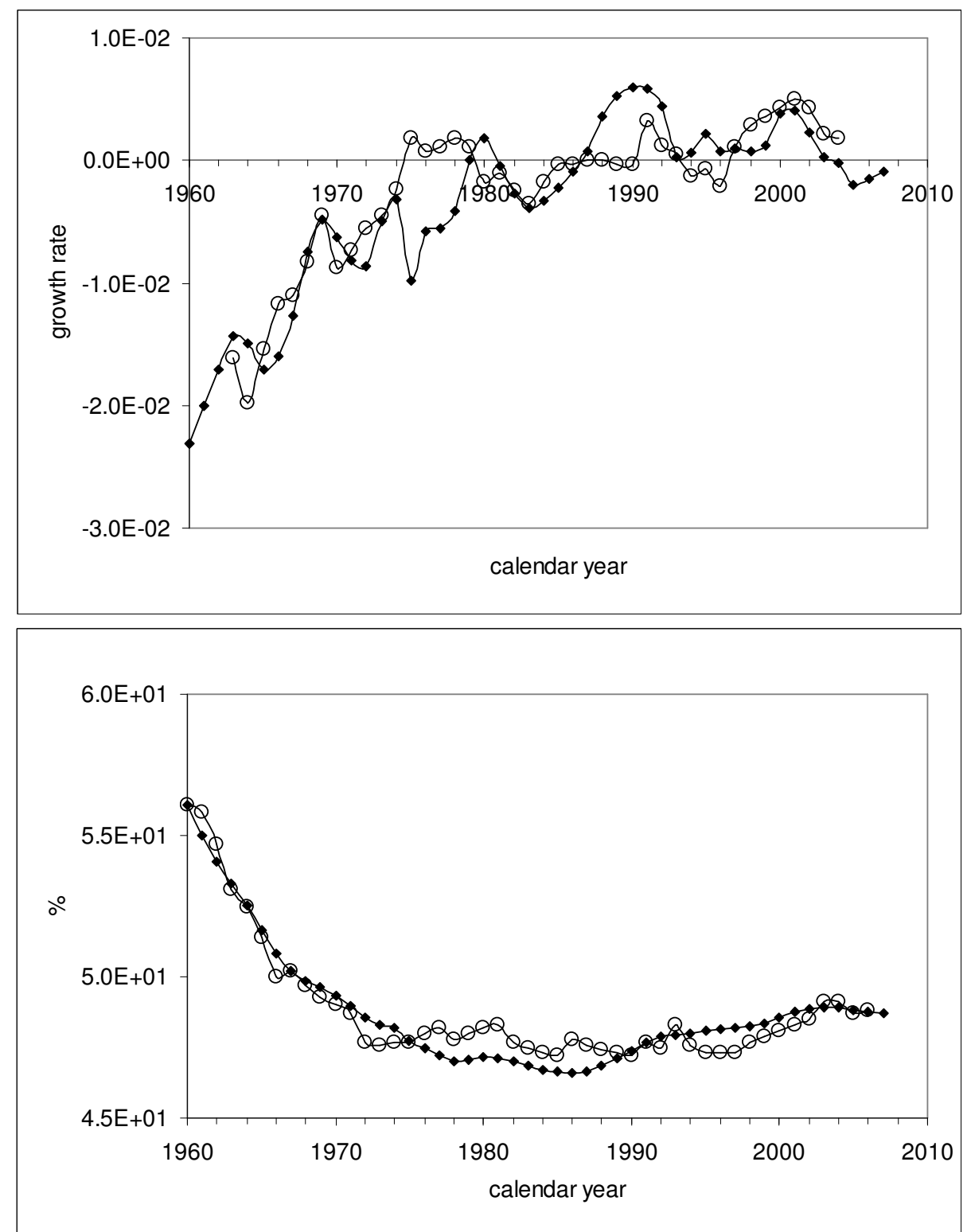

Figure 10. Observed $[\mathrm{MA}(5)]$ and predicted growth rate of LFP in Italy: $N(1959)=570000$, $A_{2}=\$ 270$ (1990 U.S. dollars), $B=1.3 \mathrm{E}+7, C=-0.0667, T=0$. For the period between 1963 and 2006, a linear regression gives the goodness-of-fit, $\mathrm{R}^{2}=0.71$.

The lower panel depicts the original LFP, changing in the range from $56.1 \%$ in 1960 to $47.2 \%$ in 1984, and the predicted LFP. 

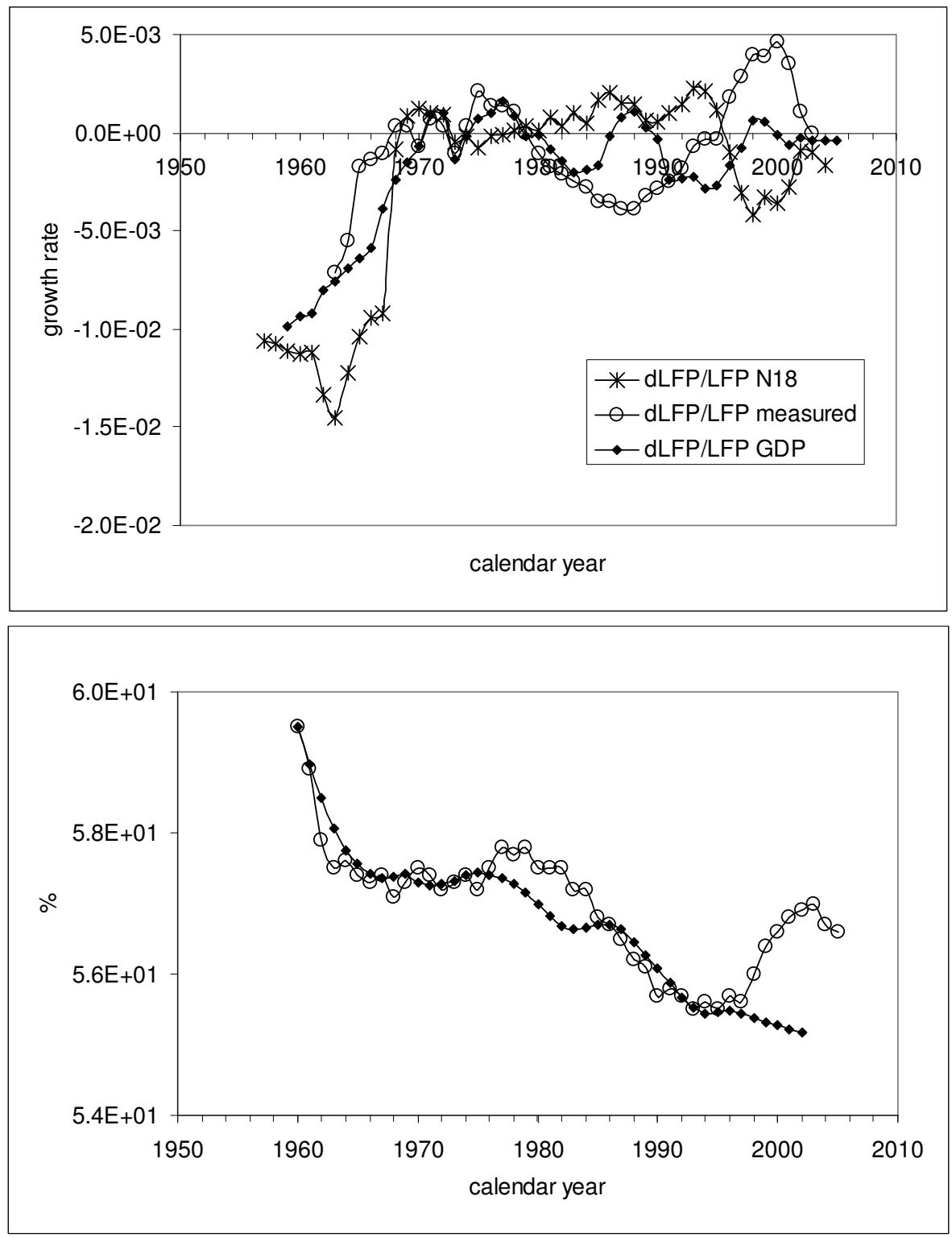

Figure 11. Observed and predicted growth rate of LFP in France: $N(1959)=570000, A=\$ 290$ (1990 U.S. dollars), $B=2.0 \mathrm{E}+7, C=-0.0425, T=0$. For the case with $N 18: B=2.4 \mathrm{E}+7, C=-0.035$. The lower panel depicts the original LFP, changing in the range from $59.5 \%$ in 1960 to $55.5 \%$ in 1995, and the predicted LFP. 

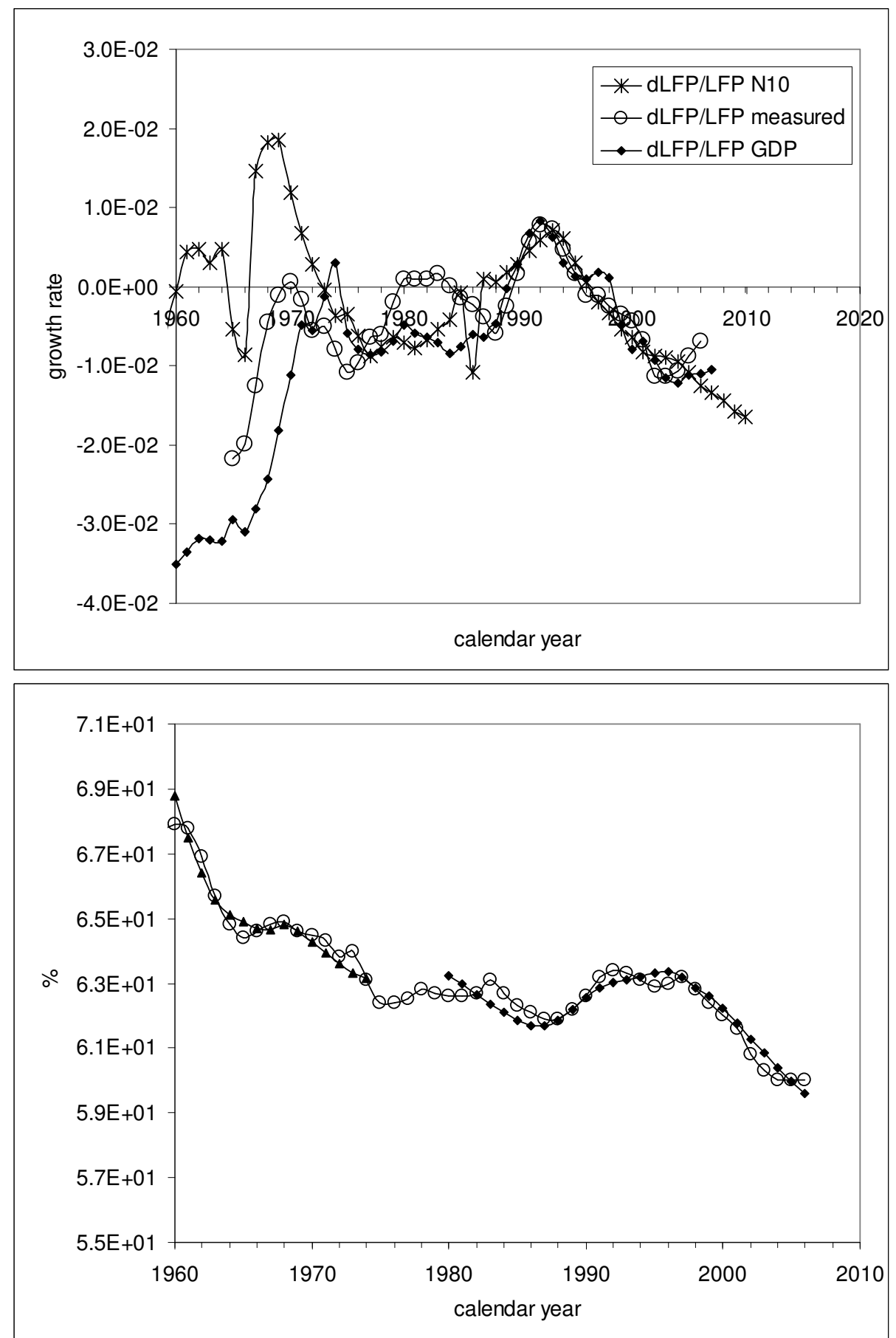

Figure 12. Observed and predicted growth rate of LFP in Japan: $N(1959)=1570000, A=\$ 390$ (1990 U.S. dollars), $B=6.5 \mathrm{E}+7, C=-0.048, T=0$. For the case with $N 18: B=3.5 \mathrm{E}+7, C=-0.052$.

The lower panel depicts the original LFP, changing in the range from $68 \%$ in 1960 to $61 \% \%$ in 2005, and the predicted LFP. The latter consists of two separated segments. We failed to predict LFP between 1972 and 1978. 

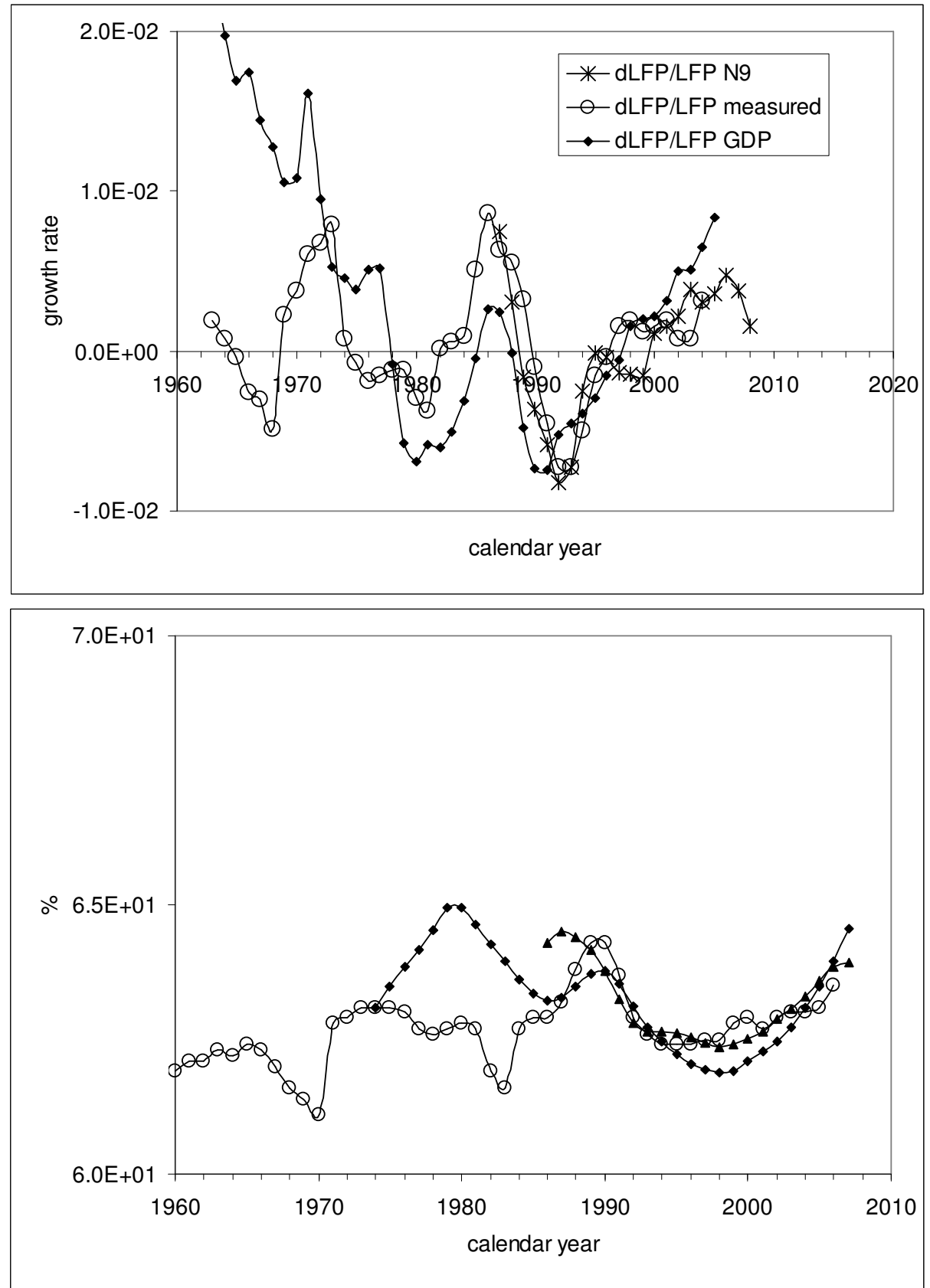

Figure 13. Observed and predicted growth rate of LFP in the UK: $N(1959)=570000$, $A_{2}=\$ 340$ (1990 U.S. dollars), $B=6.0 \mathrm{E}+7, C=-0.062, T=0$.

For the case with $N 9$ : $B=1.15 \mathrm{E}+7, C=-0.064$.

The lower panel depicts the original LFP, changing in the range from $61 \%$ in 1970 to $64.5 \%$ in 1990, and the predicted LFP. 

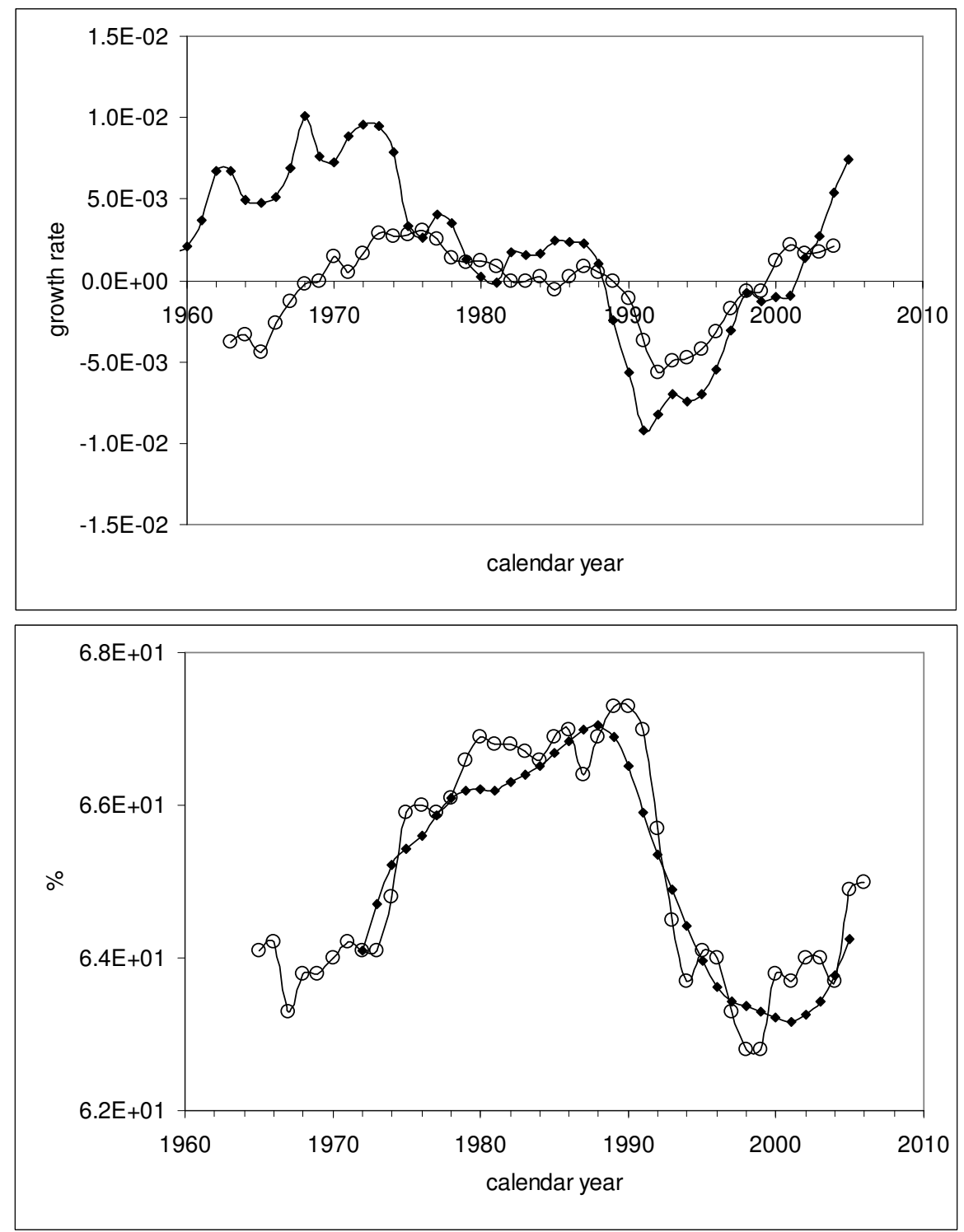

Figure 14. Observed and predicted growth rate of LFP in Sweden: $N(1959)=100000, A_{2}=\$ 310$ (1990 U.S. dollars), $B=2.2 \mathrm{E}+6, C=-0.0465, T=0$.

The lower panel depicts the original LFP, changing in the range from $67 \%$ in 1990 to $62.5 \%$ in 1998, and the predicted LFP. 